\title{
Isoniazid Associated Psychosis: A Case Series of 3 Patients
}

\author{
Vineetha Bharathan Menon ${ }^{1 *}$, Rinu Shaji ${ }^{2}$, Pratibha Pereira ${ }^{3}$, Shashidhara Kuppegala Chikkaveeraiah ${ }^{4}$ \\ Madhan Ramesh ${ }^{5}$
}

1Doctoral Research Scholar, Department of Pharmacy Practice, JSS College of Pharmacy, JSS University, Mysore- 15, Karnataka, INDIA.

2Pharm.D Intern, Department of Pharmacy Practice, JSS College of Pharmacy, JSS University, Mysore- 15, Karnataka, INDIA.

${ }^{3}$ Associate Professor, Department of General Medicine, JSS Medical College \& Hospital, JSS University, Mysore- 15, Karnataka, INDIA.

${ }^{4}$ Associate Professor, Department of General Medicine, JSS Medical College \& Hospital, JSS University, Mysore- 15, Karnataka, INDIA.

${ }^{5}$ Professor and Head, Department of Pharmacy Practice, JSS College of Pharmacy, JSS University, Mysore- 15, Karnataka, INDIA.

\begin{abstract}
Background: Isoniazid is the first line agent for the treatment of tuberculosis. Psychosis is a known complication of isoniazid therapy, although infrequent. Case report: One female and two male patients aged 35 years, 55 years and 60 years respectively developed psychosis following isoniazid administration. All the three received 300 mg of isoniazid daily for the management of pulmonary tuberculosis. High dose of isoniazid and low body mass index were identified as the common risk factor for the development of isoniazid associated psychosis. The incidence, possible pathogenesis, risk factors and treatment options are discussed. Conclusion: Isoniazid psychosis is a major complication, which if recognized early can be effectively treated.
\end{abstract}

Keywords: Adverse drug reaction, Anti-tubercular therapy, Case series, Isoniazid, Psychosis.

\section{INTRODUCTION}

Tuberculosis infects more than one-third of the population worldwide. ${ }^{1}$ Isonicotinic acid hydrazide or isoniazid (INH) was first discovered in 1912 and was later introduced by Robitzek more than half a century ago in 1952 for the treatment of tuberculosis. ${ }^{2,3}$ It is one of the first line agents used along with rifampicin (RIF), pyrazinamide (PZA), ethambutol (EMB) and streptomycin (STM) in the prevention and treatment of Mycobacterium tuberculosis infection, ${ }^{1-3}$ and it is the most potent, least toxic, and most cost effective of all anti-tubercular drugs. ${ }^{2-4,5}$ The common adverse drug reactions (ADRs) observed with INH include peripheral neuropathy, hepatitis, and rash. ${ }^{2-46}$ Cerebellar symptoms, psychosis and convulsions have been rarely reported on conventional doses of this drug. ${ }^{2-5,6}$

\section{CASE SERIES}

\section{Case 1}

A 35-year-old married female was presented to the emergency medicine department of a tertiary care hospital with complaints of abnormal behaviour characterised by agitation, excessive irrelevant talking, decreased sleep and appetite for the past 1 month. She had previous history of chronic chough with expectoration, fever with chills and rigors and progressive weight loss and had been diagnosed as a case of sputum positive pulmonary tuberculosis two months back with positive radiological findings on chest $\mathrm{x}$-ray suggestive of right sided mid zone opacity with cavity. In view of this, she was started on category 1 anti-tubercular therapy (INH $300 \mathrm{mg}$ / day, RIF 600 mg/day, PZA 1.5 gm/day, EMB $800 \mathrm{mg} /$ day and pyridoxine 20
DOI: 10.5530/ijopp.10.2.29

Address for correspondence: Vineetha Bharathan Menon, Doctoral Research Scholar, Department of Clinical Pharmacy, JSS Medical College \& Hospital and Department of Pharmacy Practice, JSS College of Pharmacy, JSS University, Mysore- 15, Karnataka, INDIA. Phone no: 091-953-828-3470, E-mail: vineethamenon54@ yahoo.com 
$\mathrm{mg} /$ day). Her past record was insignificant for any other comorbidities. There was no past personal or family history of any psychiatric disorders.

Patient weighed $35 \mathrm{~kg}$ and body mass index (BMI) was estimated as $13.17 \mathrm{~kg} / \mathrm{m}^{2}$. Her blood pressure (BP) and pulse rate (PR) at admission were recorded as $140 / 80 \mathrm{mmHg}$ and 76 beats $/ \mathrm{min}$. Clinical examination revealed that all body systems were within normal limits. A detailed psychiatric opinion was sought in which her biological functioning was found to be impaired and she was found to be illkempt and groomed, restless and wandering, and exhibited severe psychomotor agitation. Her rate of speech was increased and her thought process was characterised by loosening of association along with echolalia, while no kind of hallucinations were reported. There was no signs of neurological deficit (focal weakness, cranial nerve involvement, sign of meningeal irritation) and fundus examination was found to be normal. Her radiological investigation of brain using computed tomography did not reveal any significant findings. Her haematological and biochemical examinations were also within normal limits. In view of patient's history and clinical findings, an initial diagnosis of pulmonary tuberculosis with INH induced psychosis was considered.

The patient's acute agitation was managed by intravenous lorazepam ( $2 \mathrm{mg} / 2 \mathrm{ml}$ per day) and haloperidol (10 mg/2 ml per day). Other medications started in the patient were oral risperidone $(4 \mathrm{mg} /$ day), trihexyphenidyl (4 mg/day), quetiapine (100 mg/day), olanzapine (10 mg/day), amisulpride $(200 \mathrm{mg} /$ day $)$ and intravenous promethazine $(25 \mathrm{mg} / 2 \mathrm{ml}$ per day). Patient was restarted on modified anti-tubercular therapy without INH, specifically RIF $450 \mathrm{mg} /$ day, EMB $600 \mathrm{mg} /$ day and PZA $750 \mathrm{mg} /$ day. Patient's condition improved over the next two days. She was discharged on oral risperidone/trihexyphenidyl $8 / 4$ $\mathrm{mg} /$ day and amisulpride $400 \mathrm{mg} /$ day along with the modified anti-tubercular therapy and was asked for review after 1 week. On review her condition had improved and patient was doing considerably well. Over the next three months follow up, patient did not have any psychiatric manifestations.

The Naranjo's criteria and WHO probability scale were applied to determine the causality for suspected ADR. The causality assessment with both scales revealed that the ADR due to INH in this case was 'probable' (Naranjo overall score: 6). Severity of the ADR was evaluated using the Modified Hartwig and Siegel scale, based on which it was categorized as moderate (level 4(b)) reaction.

\section{Case 2}

A 55-year-old male patient, weighing $56 \mathrm{~kg}$ with BMI of $18.08 \mathrm{~kg} / \mathrm{m}^{2}$, was brought to a tertiary care hospital with complaints of abnormal behavior characterized by agitation, excessive irrelevant talking, auditory and visual hallucination since the past 1 week. Two months back he was admitted to the hospital with history of chronic chough, difficulty in breathing and fever associated with generalized weakness. In view of his clinical presentations and chest x-ray which showed bilateral diffuse opacities, he was diagnosed as a case of pulmonary tuberculosis and was started on category 1 anti-tubercular therapy (INH $300 \mathrm{mg} /$ day, RIF $600 \mathrm{mg} /$ day, PZA $1.5 \mathrm{gm} /$ day, EMB $800 \mathrm{mg} /$ day and pyridoxine 20 $\mathrm{mg} /$ day). He had no past personal or family history of any mental or psychiatric disorders or any other concomitant diseases. He had been a chronic smoker since 20 years.

Patient's BP was recorded to be $126 / 80 \mathrm{mmHg}$ and PR was 98 beats/min. He was hemodynamically stable. The mental status examination showed that the patient had altered sensorium. He was also found to be anxious and agitated. He had bizarre behavior, crying, agitation, auditory and visual hallucinations, delusions of reference, disorganized speech and thinking. There was no specific neurological deficit and his computed tomography- head were also not significant. On investigation his hematologic, biochemical and urine examination was normal. Based on subjective and objective evidences, a provisional diagnosis of pulmonary tuberculosis with drug induced psychosis were considered.

Patient was put on intravenous lorazepam $(2 \mathrm{mg} / 2$ $\mathrm{ml}$ per day) and haloperidol $(10 \mathrm{mg} / 2 \mathrm{ml}$ per day) for management of acute agitation. Other medications started in the patient were oral risperidone (4 $\mathrm{mg} /$ day), quetiapine (50 mg/day), clonazepam ( 0.5 $\mathrm{mg} /$ day) and pyridoxine $(40 \mathrm{mg} /$ day). All the antitubercular therapy except INH were continued and patient was discharged with the antipsychotic drugs (risperidone and quetiapine) and pyridoxine $40 \mathrm{mg} /$ day. Within two weeks of this treatment, patient showed marked improvement in mental condition. Rechallenge with INH was done and there was reappearance of symptoms thereby confirming diagnosis of INH associated psychosis. Patient restarted on modified anti-tubercular therapy with RIF 450 $\mathrm{mg} /$ day, EMB $800 \mathrm{mg} /$ day, STM $750 \mathrm{mg} /$ day and ofloxacin $400 \mathrm{mg} /$ day. Patient's condition improved over the next week and on review a month later he was doing considerably well. There were no further psychiatric manifestations. 
Causality was assessed by using both Naranjo's criteria and the World Health Organization probability scale, which revealed a 'definite' (score 9) causal relationship between the drug and the adverse event. Severity of the reaction was evaluated using the Modified Hartwig and Siegel scale and was categorized as moderate (level 4 (b) reaction) in its severity.

\section{Case 3}

A 60-year-old married male was admitted to the emergency medicine department of a tertiary care hospital with complaints of vomiting (3 episodes) since morning and abnormal behavior characterized by irritability, restlessness, occasional violent behavior, irrelevant talking, decreased sleep and appetite for past 2 days. He was diagnosed with pulmonary tuberculosis 20 days back in view of his clinical presentation of chronic chough with expectoration and fever and positive radiological findings on chest x-ray (bilateral upper zone reticulonodular shadows) and was started on 4 drugs regimen (INH $300 \mathrm{mg}$ / day, RIF 600 mg/day, PZA 1.5 gm/day, EMB 800 $\mathrm{mg} /$ day and pyridoxine $20 \mathrm{mg} /$ day). He was also a known case of type II diabetes mellitus since 12 years and was on regular treatment with insulin 16-0-12. There was no past personal or family history suggestive of any psychiatric illness and his premorbid personality was good. The patient had no history of smoking, alcohol or drug abuse.

On examination patient was found to be irritable, restless, oriented to time, place and person, and non-cooperative. His cardiovascular, respiratory and abdominal systems were within normal limits. Patient weighed $52 \mathrm{~kg}$ and BMI was estimated as $16.79 \mathrm{~kg} / \mathrm{m}^{2}$. His $\mathrm{BP}, \mathrm{PR}$ and respiratory rate $(\mathrm{RR})$ were $120 / 80 \mathrm{mmHg}, 80$ beats/min and 17 cycles/ min respectively, at admission. Patient had relative neutrophilia and elevated erythrocyte sedimentation rate (ESR) $[50 \mathrm{~mm} / \mathrm{hr}(0-10 \mathrm{~mm} / \mathrm{hr})]$. Arterial blood gas analysis showed $\mathrm{pH} 7.447, \mathrm{pCO} 2$ 31.9, pO2 93.3, $\mathrm{BE}$ 1.1, $\mathrm{HCO} 3$ 21.6, O2 sat 97.3, lactate 0.9, anionic gap 6.8. His hemoglobin A1c (HbA1c), fasting blood sugar (FBS) and post prandial blood sugar (PPBS) were 10.9 (poor control and needs monitoring), $380 \mathrm{mg} / \mathrm{dL}(70-110 \mathrm{mg} / \mathrm{dL}$ ) and $345 \mathrm{mg} / \mathrm{dL}$ (80$150 \mathrm{mg} / \mathrm{dL}$ ) respectively. Urea was $86 \mathrm{mg} / \mathrm{dL}(15-40$ $\mathrm{mg} / \mathrm{dL})$, creatinine was $2.1 \mathrm{mg} / \mathrm{dL}(0.7-1.4 \mathrm{mg} / \mathrm{dL})$, sodium was $130 \mathrm{mEq} / \mathrm{L}(136-145 \mathrm{mEq} / \mathrm{L})$, potassium was $5.7 \mathrm{mEq} / \mathrm{L}(3.5-5.0 \mathrm{mEq} / \mathrm{L})$, chloride was $92 \mathrm{mEq} / \mathrm{L}(95-110 \mathrm{mEq} / \mathrm{L})$, albumin was $3.36 \mathrm{gm} /$ $\mathrm{dL}(3.5-5.2 \mathrm{gm} / \mathrm{dL})$ and total proteins was $5.21 \mathrm{gm} /$ $\mathrm{dL}(6-8 \mathrm{gm} / \mathrm{dL})$. Urine analysis showed presence of large ketone bodies, traces of albumin, plenty of pus cells and 8-10 RBCs. His computed tomography of brain showed no abnormalities. He was provisionally diagnosed as starvation ketoacidosis with type 2 diabetes mellitus with pulmonary tuberculosis with INH induced psychosis.

The patient's irritability and restlessness was managed by intravenous lorazepam $(2 \mathrm{mg} / 2 \mathrm{ml}$ per day) and haloperidol $(10 \mathrm{mg} / 2 \mathrm{ml}$ per day). Other antipsychotic medications started in the patient was oral risperidone ( $4 \mathrm{mg} /$ day) and quetiapine $(50 \mathrm{mg} /$ day) $\mathrm{He}$ was also put on intravenous ceftriaxone $2 \mathrm{gm} /$ day, intravenous ondansetron $12 \mathrm{mg} /$ day, intravenous pantoprazole $40 \mathrm{mg} /$ day, oral ofloxacin 400 $\mathrm{mg} /$ day, insulin infusion (10 U thrice daily), intravenous vitamin B complex and oral pyridoxine $40 \mathrm{mg} /$ day. Patient was restarted on modified anti-tubercular therapy excluding INH. Arterial blood gas analysis, hemogram, kidney function tests, and liver function tests were all repeated and were found to be within normal limits. Patient's medical condition and mental state also improved over the one week. $\mathrm{He}$ was discharged with risperidone, quetiapine and insulin injection ( $20 \mathrm{U}$ thrice daily) along with the modified anti-tubercular therapy comprising of RIF $600 \mathrm{mg} /$ day, EMB $800 \mathrm{mg} /$ day, PZA $1000 \mathrm{mg} /$ day, ofloxacin $400 \mathrm{mg} /$ day and pyridoxine $40 \mathrm{mg} /$ day. A month after commencement of treatment, on review, his condition was found to be satisfactory and did not have any psychiatric manifestations.

The ADR was probable as assessed by the Naranjo casualty scale and the World Health Organization probability scale and was found to be 'probable' with a score of 6 . Severity of the reaction was assessed using Hartwig ADR Severity Assessment Scale which classified it into level 4(b) (moderate severity).

\section{ETHICAL CLEARANCE}

The case series above were prepared in accordance with the principles proposed in the Declaration of Helsinki.

\section{DISCUSSION}

Psychosis associated with therapeutic doses of INH occurs infrequently, but its actual incidence is not well established.7 The first description of psychotic symptoms due to INH was given by Mandel et al in 1956..$^{4-8}$ Various mechanisms has been suggested but the exact mechanism is not clearly understood, but $\mathrm{INH}$ is known to interfere with several metabolic pathways essential for normal neuronal functioning. ${ }^{2-49} \mathrm{INH}$ lowers the pyridoxine concentration by 
increasing its excretion, which in turn causes disturbance in the normal tryptophan metabolism. INH metabolites inhibit the activation of pyridoxine to pyridoxal 5-phosphate. Pyridoxal-5-phosphate is a cofactor of glutamic acid decarboxylase that catalyzes the conversion of glutamic acid to gamma aminobutyric acid (GABA), resulting in depletion of brain levels of GABA. ${ }^{2-47-9} \mathrm{INH}$ also causes inhibition of enzyme monoamine oxidase, thereby leading to increased concentration of cathecholamines and serotonin..$^{1-3}$

According to the literature, susceptibility increases with old age, personal and family history of psychiatric disorders, malnutrition, alcohol intake, diabetes, renal and hepatocellular insufficiency, hyperthyroidism etc. ${ }^{1-4-9,10}$ However malnutrition was the only identifiable risk factor among these in our patients. The weight of all our study patients were below the ideal requirements. Malnutrition can cause psychosis as the amino acids, that are needed to make various neurotransmitters in the central nervous system, are depleted. ${ }^{9}$

Another possible reason for acute onset of psychosis may be the pharmacokinetic properties of the drug. ${ }^{1}$ INH is rapidLy absorbed from the gastrointestinal tract and peak levels are reached within 1 to $2 \mathrm{~h}$ of ingestion of a therapeutic dose. ${ }^{7}$ It has been found that about $40 \%$ of Indian population are slow acetylators, thus causing slow metabolism leading to drug accumulation and thus more side effects. ${ }^{1}$ The risk also increases when the dose of INH is above $5 \mathrm{mg} /$ $\mathrm{kg}$, but also has been recorded on low dosage..$^{10,11}$ If the dose of INH was to be calculated based on the individual body weight, then all our patients received high dose of the drug, which possibly could have increased the susceptibility to the adverse effect. The adverse effects are also more common among patients in whom pyridoxine is not supplemented; however, they are also known to affect $5 \%$ of patients on adequate pyridoxine supplementation (10-50 mg/day). All our patients received daily pyridoxine supplementation of $20 \mathrm{mg} /$ day.

According to literature, the onset of psychosis varies from days to months, with few weeks being the most common time period. ${ }^{1}$ In accordance to the previous findings, the onset of symptoms in our patients varied from 2 days to 1 month. Although reports of INH induced psychosis has been documented earlier, there is great variability in the clinical features and time of onset of symptoms of the reported cases. ${ }^{1,2-4}$ In 1957, Jackson reported five cases of INHinduced psychosis which presented with excessive argumentation, mental depression, euphoria, grandi- ose behavior, and complex delusions; none of these patients had any previous history of mental disorders. Agarwala, in 1974, reported symptoms of restlessness, irritability, emotional instability, agitation, apprehension, and fluctuation in behavior following INH use (consistent with the symptoms observed in our patient). Bedi, in 1994, reported a case of INHinduced psychosis characterized by restlessness, irritability, aimless activity, and incongruous actions after starting INH therapy. In 1996, Tiwari reported a case of INH-induced psychosis with disturbed sleep, restlessness, and abnormal behavior, similar clinical features were observed in our patients as well. The duration of psychotic symptoms in these case reports varied widely, i.e., 7-45 days, 7 days, 10 days, and 120 days respectively. ${ }^{2-4}$

The usual approach to treat INH induced psychosis is to withdraw the drug, treat the psychosis and then gradually re-introduce INH at lower dosage after psychosis has completely resolved. ${ }^{5-9-11}$ Some authors have suggested the use of pyridoxine in high doses following INH dechallenge, while others have recommended the use of antipsychotics along with high dose pyridoxine. Studies have found that in cases where psychiatric symptoms are not very severe, INH can be continued along with novel antipsychotics like risperidone, olanzapine in treating the psychiatric manifestation. ${ }^{12}$ In all our study patients, INH was dechallenged and patients were treated with a combination of antipsychotics and pyridoxine. Rechallenge in one patient resulted in re-occurrence of symptoms. All patients were started on second line anti-tubercular therapy. Recovery took months, as reported in the literature. ${ }^{9}$

\section{CONCLUSION}

Tuberculosis is more prevalent in developing countries like India. Thus physicians should be aware about the drug toxicity profiles of anti-tubercular drugs like INH. Iatrogenic psychiatric complications can greatly impact the patients' quality of life and as physicians' attitude towards use of INH, therefore successful control of these complications is crucial. This case report thus highlights the psychiatric clinical presentation following INH initiation and adds to further literature on INH inducing psychosis.

\section{CONFLICT OF INTEREST}

The authors report no conflict of interest that is directly relevant to the content of the case series. 


\section{ACKNOWLEDGEMENT}

Authors would like to thank JSS University for the constant support and encouragement.

\section{ABBREVIATIONS USED}

ADRs: Adverse Drug Reactions; BMI: Body Mass Index; BP: Blood Pressure; EMB: Ethambutol; ESR: Erythrocyte Sedimentation Rate; FBS: Fasting Blood Sugar; GABA: Gamma Aminobutyric Acid; HbA1c: Hemoglobin A1c; INH: Isonicotinic acid hydrazide (or) Isoniazid; PPBS: Post Prandial Blood Sugar; PR: Pulse Rate; PZA: Pyrazinamide; RIF: Rifampicin; RR: Respiratory Rate; STM: Streptomycin.

\section{REFERENCES}

1. Arya S, Sukhija G, Singh H. Acute psychosis after recent isoniazid initiation. Journal of clinical and diagnostic research: JCDR. 2015 Jun;9(6):VD01.
2. Masood I, Bhat S, Beigh A, Gupta V. Isoniazid-induced psychosis in a patient on DOTS therapy. Annals of Tropical Medicine and Public Health. 2011 Jul $1 ; 4(2): 126-7$

3. James A, Dan AA, George A, et al. Isoniazid induced psychosis- a case report. WJPPS. 2014;3(8):655-7.

4. Prasad R, Garg R, Verma SK. Isoniazid and ethambutol induced psychosis. Ann Thorac Med. 2008;3(4):149-51.

5. Binwal VK, Syed T, Ahir D. Isoniazid induced cerebellitis and psychosis in chronic kidney disease patient with tubercular pleural effusion. J IntegrNephrolAndrol. 2016;3(2):60-1.

6. Bedi RS. Isoniazid induced pyrexia and psychosis in a single individual. Indian Journal of Tuberculosis. 1994;41(4):269-70.

7. lannaccone R, Sue YJ, Avner JR. Suicidal psychosis secondary to isoniazid. Pediatric emergency care. 2002;18(1):25-7.

8. Demartini B, Camisasca M, Zuin M, Gambini O. A case of isoniazid-induced delirium. The Journal of neuropsychiatry and clinical neurosciences. 2013;25(2):E68-9.

9. Oninla SO, Oyedeji GA, Oninla OA, Gbadebo-Aina. Isoniazid induced psychosis in two children treated for tuberculosis: case reports and literature review. IJMPCR. 2016;6(4):1-6.

10. Vega P, Sweetland A, Acha J, et al. Psychiatric issues in the management of patients with multi-drug resistant tuberculosis. Int $\mathrm{J}$ Tuberc Lung Dis. 2004;8(6):749-59.

11. Duncan H, Kerr D. Toxic psychosis due to isoniazid. British journal of diseases of the chest. 1962;56(3):131-8.

12. Isoniazid induced psychosis- a clinical dilemma. J Indian Acad Clin Med. 2002;3(3):306-7. 